\title{
Rent-To-Own Agreements: Purchases Or Rentals?
}

Michael H. Anderson (E-mail: manderson@umassd.edu), University of Massachusetts-Dartmouth Raymond Jackson (E-mail: rjackson@umassd.edu), University of Massachusetts-Dartmouth

\begin{abstract}
The rent-to-own (RTO) business has emerged as an important component of the retailing sector. By offering immediate access to household goods for a small periodic fee without a credit check or down payment, RTO has strong appeal to low income and financially distressed consumers. A common perception of RTO is that they are disguised, high-interest installment agreements as most consumers eventually acquire the contracted merchandise by making all scheduled payments. We examine the nature of these agreements by using a unique data set of more than 350 thousand transactions drawn from 100 RTO stores in 46 states. Our main result, derived from an analysis of disposition and duration, is that RTO agreements are more frequently used for shortterm needs rather than as a method of acquisition. Legislative and legal efforts to classify RTO agreements as primarily installment contracts cannot be justified by their pattern of use in the marketplace.
\end{abstract}

\section{Introduction}

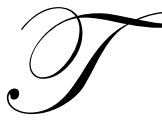

his paper presents the most complete and reliable evidence to date on the ultimate disposition of rentto-own (RTO) contracts. Such evidence, derived from data collected from RTO stores rather than consumer interviews, is relevant in determining whether RTO agreements are primarily disguised installment contracts used to finance purchases or mainly rental agreements with most consumers returning merchandise relatively quickly. Judicial rulings as well as existing and proposed legislation at the state and federal levels have been guided by studies based on interviews of a relatively small sample of RTO customers whose recollections and opinions may be inaccurate or, for a variety of reasons, less than candid. The transactional data generated from RTO stores is superior with regard to the size of the sample and in the systematic manner in which the information is collected at the retail level.

The rent-to-own business has become an important sector of the retailing industry in a relatively short time. From its beginnings in the 1960s, rent-to-own now comprises at least 8,000 stores in the United States producing revenues of over $\$ 5.3$ billion (APRO 2001). Along with its growth, rent-to-own has generated considerable controversy regarding the essential nature of the agreement and the actual cost to the consumer, a significant number of whom the Federal Trade Commission (FTC) has identified as lower income (FTC 2000).

For a comparatively small weekly or monthly fee, an RTO agreement provides the consumer with immediate access without a credit check or down payment to new or used household goods such as electronics, appliances, furniture and, more recently, personal computers. The rental fee is all-inclusive with regard to delivery, set up and service for the term of the contract. An agreement is written for a specified time period, usually 18 to 24 months, but provides the consumer with a number of options for termination. The consumer may terminate the contract early by returning the goods to the dealer for any reason or by making a purchase with a single payment of a specified proportion of the remaining scheduled rental payments, typically 50 to 60 percent (FTC 2000). Should all scheduled payments be made, the consumer takes ownership of the contracted merchandise. However, no adverse credit report, extra fee or legal obligation arises from a consumer deciding to terminate after a few or only one payment. 
The controversy about rent-to-own is based on identifying the essential nature of the agreement. One view is that rent-to-own is a disguised installment contract that exploits the lack of information and economic vulnerability of low-income consumers. As installment contracts, RTO should be strictly regulated as such by existing state and federal consumer credit laws (Freedman [1993]). In this view, the RTO item is ultimately purchased at several multiples of its normal retail price with the consumer borrowing at an usurious implicit annual percentage rate (APR). For example, Zikmund-Fisher and Parker (1999) derive an APR of 229.7 percent for an RTO agreement on a 31-inch color television. Swagler and Wheeler (1989) report that five RTO dealers in Atlanta impose APRs on televisions that range from 175 percent to 193 percent. Hill, Ramp and Silver (1998) cite a study by Consumer Reports that finds RTO customers unaware they are purchasing at APRs exceeding 250 percent. Walden (1990) examined seven television and five washer RTO contracts and found APRs on dealer investments ranging from 32.7 percent to 124.8 percent and from 88.3 percent to 116.8 percent, respectively.

An alternative view sees RTO as a hybrid rental and purchase agreement with embedded options (Anderson and Jackson [2001]). In this formulation the contract has an initial rental phase which is followed by an installment phase during which time an implicit loan is paid off. In the rental phase the consumer acquires (1) immediate access to a needed appliance, furniture, computer, or electronic equipment; (2) a valuable embedded put option that can be exercised to cancel the agreement without negative financial repercussions; (3) an option to purchase at a predetermined proportion of the remaining rental fees; and, (4) an option to secure an installment agreement at a competitive APR after the rental phase is completed. During the installment phase the consumer makes periodic payments on the implicit loan at a competitive interest rate but still retains the right to buy for a specified price or to exercise the embedded put to cancel, though the value of this later option declines with time.

The validity of these alternative views depends heavily on an empirical examination of the ultimate disposition of the agreements. Those advocating the view that RTO is a disguised installment agreement rely on evidence that the vast majority of customers intend to acquire the merchandise and that a high proportion of those customers actually do so by making all payments to term. The alternative view that RTO is a serially structured agreement with rental and installment phases depends on evidence that consumers frequently exercise the embedded options to terminate or purchase in the rental phase and that the put option to cancel is seldom exercised in the installment phase.

The next section reviews the current sources of information and statements regarding the ultimate disposition of RTO contracts. The succeeding two sections analyze comparable information derived from a large number of RTO transactions gathered from the retail stores themselves. An examination of the transactional data provides a far more realistic and richer profile of the RTO business than has been portrayed through interviews of former and current customers. The final section discusses the policy implications of the empirical results.

\section{Evidence On The Disposition Of RTO Agreements Based On Interviews}

Though the evidence is thin and often does not address the issue of rental or purchase directly, it is widely accepted that the majority of RTO customers intend to acquire the contracted merchandise and a very significant number of these customers actually do so. This is perhaps the most compelling argument in the ongoing efforts of consumer groups and other advocates urging the courts and state and federal legislatures to regard an RTO contract as a variation of an installment sales agreement and therefore subject to the same consumer credit laws including the Truth in Lending Act and the Fair Credit Reporting Act.

A comprehensive source of information on the rent-to-own industry is the longitudinal study of Rent-ACenter (RAC) customers by the consulting firm Cheskin+Martin (1993). This study reported that 70 percent of the sample of 1,604 then current RAC customers anticipated owning the item by renting to term and that 74 percent of previous users had acquired ownership of at least one item through an RTO agreement.

In a survey of 58 RTO customers who had completed or terminated their contracts, Zikmund-Fisher and Parker (1999) found that 76 percent became owners by making all the stipulated payments. Without referring to any specific study, Ramp (1993) testified that the RTO industry's studies indicate at least 70-80 percent of customers 
intend to buy the goods and well over 50 percent complete their contracts to term. Hill, Ramp and Silver (1998) refer to a case in the Wisconsin courts where the plaintiff claims that 86 percent of RAC customers in that state desire to acquire ownership of the merchandise eventually.

The recent FTC (2000) telephone survey of RTO users supports the thesis that a large majority of agreements result in purchase where purchase is defined as customers making rental payments to term or using the early purchase option. The FTC's nationwide, random sample of 532 customers indicates that 67 percent intended to acquire the merchandise at the time it was rented and that 87 percent of customers who had intended to acquire the merchandise actually did (FTC 2000).

The FTC study also investigated the disposition of 515 RTO agreements made two years prior to the interviews and found that 71 percent of the merchandise had been acquired, 25 percent had been returned to the retail store and 2 percent was still being rented (FTC 2000). This empirical evidence suggesting a high purchase rate led the FTC's Bureau of Consumer Protection, in testimony before a subcommittee of the House Financial Services Committee, to urge that "the industry recognize this important fact... it is important that consumers know about the basic terms of the rent-to-own transaction, in particular the total cost of purchase" (FTC 2001). Relying on the FTC's purchase rate estimate, the Division of Consumer and Community Affairs of the Federal Reserve Board (2001) offered concurring testimony on the need for merchandise tags showing the total cost to purchase the item.

\section{Disposition Of RTO Agreements Based On Transactional Data}

The analysis of transactional data collected from RTO retailers provides a different and more complex picture of the disposition of the contracted merchandise and of the rent-to-own business itself. We find that in less than $39 \%$ of agreements does the customer acquire the item either by renting to term or though an early purchase. In addition, a majority of agreements terminate with the return of merchandise within a relatively short time period. The data reveals also another important classification in the disposition list that is entirely absent from the interview data. Namely, a significant number of agreements are terminated by the customer stopping payments and essentially disappearing ("skipping") along with the merchandise, an outcome not likely to be uncovered by consumer responses in a telephone survey or interview.

With the cooperation of the Association of Progressive Rental Organizations (APRO), proprietary transactional data from the 1991- 2001 time period was collected from 100 stores in 46 states in the United States including 57 Rent-A-Centers and 43 other RTO stores. At the individual store level, all available transactional data was gathered, filtered only to remove personal information to ensure consumer privacy. The APRO facilitated access to the raw data used in this research without prior conditions or constraints. As many transactions as possible were collected given each store's data storage constraint. Due to the systematic purging of older data at the store level to make room for current transactions, 95 percent of the data set consists of transactions originating from 1998-2001.

The resulting 352,646 raw transactional records were classified as (1) returned-agreement terminated with the return of the merchandise; (2) charged off-agreement terminated and the merchandise remained with the customer; (3) active - rental payments still being made at this date; (4) void-agreement terminated immediately at inception for some reason; and, (5) transferred out-agreement transferred to another store possibly because the client moved. The results of this classification are shown in Table 1.

The analysis of concluded and still active agreements shown in Table 1 contradicts the perception of RTO contracts derived from small sample interviews of customers that the primary use of an agreement is acquisition. Over half, 53.03 percent, of the agreements were cancelled by the customer or by the store with merchandise returned. In far fewer numbers, 22.67 percent, was the agreement charged off with the merchandise remaining in the customer's possession. The percentage of RTO agreements resulting in purchase or payment to term is a subset of charged off and only 16.81 percent of the transactions in the database. The evidence suggests that acquisition by the consumer derived from a specific agreement is far less frequent than believed. Of all agreements in the database, 19.08 percent were still active and a small percentage voided or transferred. 
Table 1. Classification of the Transactional Data and Comparable FTC Data

\begin{tabular}{lcccc}
\hline & \multicolumn{2}{c}{ Transactional Data } & \multicolumn{2}{c}{ FTC Data } \\
\multicolumn{1}{c}{ Category } & Number & \% of Total & Number & \% of Total \\
\hline Returned & 186,998 & $53.08 \%$ & 342 & $26.91 \%$ \\
Charged Off & 79,933 & 22.67 & - & - \\
$\quad$ Purchased or Paid to Term & 59,296 & 16.81 & 616 & 48.47 \\
Active & 67,287 & 19.08 & 286 & 22.50 \\
Void & 15,648 & 4.44 & - & - \\
Transferred & 2,780 & 0.79 & - & - \\
Other & - & - & 27 & 2.12 \\
Total & 352,646 & $100.00 \%$ & 1,271 & $100.00 \%$ \\
\hline
\end{tabular}

In the table, "Purchased or Paid to Term" is a sub-category of "Charged Off".

Comparable data reported by the FTC (2000), also shown in Table 1, is the reverse of our findings on the key issue of returns relative to purchases. The FTC survey of 1,271 current and former customers found that 26.9 percent of the goods were returned instead of 53.03 percent, and 48.5 percent of the agreements ended with a purchase or payments to term instead of 16.81 percent.

Some of this variance can be attributed to a difference in the method of data collection. The FTC survey relies on customer responses while this study uses actual transactions as the metric. The transactional data is inclusive in that all agreements are in the database regardless of whether the outcome was favorable or unfavorable to the dealer or customer. The bias in the FTC survey is towards over-reporting of acquisition since this is likely to be perceived as a positive outcome by the client. Returns, particularly if involuntary, may be perceived negatively and be under-reported. Consumers who rent an item several times through multiple agreements before eventually taking ownership also enhance the bias in the FTC survey towards acquisition. The FTC survey would likely record the item only as an acquisition without sufficient information to tabulate the number of prior agreements ending in return.

The FTC telephone survey also relied on the accuracy of the response of the person contacted. Details of an RTO agreement may not be recalled precisely after as many as five years have elapsed. This point is supported by the evidence in Table 1 on the proportion of active agreements. In this category, where dependence on recall is clearly not an issue, the FTC reports 22.5 percent of agreements still active, a very close match to our transactional database of 19.08 percent active.

The statistics in Table 1 emphasizing merchandise returns strongly suggests that the RTO business is heavily involved in adding returned or recovered merchandise to inventory in order to be re-rented through new agreements. This view is consistent with the Cheskin+Martin (1993) survey that found 41 percent of 1,604 customers claim to have rented used items.

One might be concerned that the large volume of transactional data is misleading since it is being generated by relatively few customers who are encouraged, as an RTO industry strategy, to sign and cancel a series of costly agreements. During this time period, the relationship between customers and agreements in the database reveals an average of 1.9 agreements per customer with 55 percent of customers having one agreement, and 90 percent with three or fewer RTO transactions. These results tend to discount the presence of an extraordinary high volume of agreements per customer.

In order to focus only on RTO agreements that were initiated and eventually terminated, the inactive categories charged off and returned are examined in greater detail. The categories active, void, and transferred are excluded as they represent ongoing agreements where rental payments are still being made, agreements never activated, or agreements not concluded by purchase or return at that particular store, respectively. In addition to exclud- 
ing these categories it is necessary to refine the relevant data set to adjust for the problem of right-censored and leftcensored data.

The right-censored problem leads to an over representation in the raw data set of merchandise returns relative to charge offs. If all recently originated but concluded agreements are counted, most of the returns will be included since they typically have a short duration. However, most agreements eventually resulting in purchase or payment to term are of greater duration and are likely to be excluded by still being classified as active. To correct for this problem, the refined data set includes only agreements that originated at least 1.6 years prior to the end point of the collection period. This restriction was chosen because $95 \%$ of all agreements in the sample were originated and concluded in less time thus correcting for the under representation of charged off agreements.

The left-censored data problem results in a bias among older agreements towards purchase and payments to term because the completed shorter duration rentals have already been systematically purged at the start of the data collection period in 1991. To correct for this bias we include only agreements in the database that originated no more than 3.4 years from the end of the data collection period in 2001. This restriction was chosen as $95 \%$ of all agreements in the sample were no older than 3.4 years thus correcting for under representation of returns among older agreements. After adjusting the data set for bias, the remaining transactions still included all 100 stores but the 1991-2001 time interval narrowed to 1997-1999.

Agreements in the charged off category are classified according to the reason for termination: (1) purchased - the consumer paid a lump sum to buy before term; (2) payments to term - customer made all the rental payments and owns the merchandise; (3) customer skipped-whereabouts of the customer and the goods is unknown; (4) item stolen - agreement terminated because the customer reports a theft; and, (5) item damagedagreement terminated because the customer reports the item has been damaged and is not serviceable.

The returned category is also classified by reason for the return and includes: (1) short-run rentalcustomer states there was only a temporary need; (2) collection problem-store retrieved merchandise due to lack of payment; (3) affordability - customer states that agreement is not affordable or too costly; (4) exchanged — customer exchanges one item for another getting a new agreement; (5) loss of income - customer reports income reduced due to loss of employment or other reason; (6) no payment made - first payment never made and merchandise is retrieved; and, (7) service problem - merchandise returned because of unsatisfactory service or performance.

The information reported by each store for all classifications in the charged off category is based on factual events and should therefore be highly reliable. Whether a customer is reported to have made all payments, purchased early or skipped is not subject to the discretion or judgment of the employee recording the information. The same degree of reliability cannot be inferred from the raw data generated for all classifications in the returned category. While collection problem, exchanged and service problem are based on factual events; agreements assigned to the remaining classifications depend on the attitude and motivations of the responding customer. Assuming a customer places a high value on privacy or is reluctant to reveal negative personal information, the reason given for the return will be short-term rental rather than affordability or loss of income. As is the case with the FTC and other interview results, the aggregated data is likely to overestimate the number of merchandise returns motivated by the end of a short-term need and underestimate those caused by the continued burden or exacerbation of economic hardship. 
Table 2. Disposition of Agreements Classified as Charged Off or Returned (Adjusted for Right and Left Censored Data)

\begin{tabular}{lrcc}
\hline Category & Number & \% of Group & \% of Agreements \\
\hline Charged Off & $\mathbf{4 6 , 0 3 7}$ & $\mathbf{1 0 0 . 0 0 \%}$ & $\mathbf{4 8 . 4 0 \%}$ \\
Purchased & 25,804 & $56.05 \%$ & $27.13 \%$ \\
Payments to Term & 11,376 & 24.71 & 11.96 \\
Customer Skipped & 7,435 & 16.15 & 7.82 \\
Item Stolen & 348 & 0.76 & 0.37 \\
Item Damaged & 329 & 0.71 & 0.35 \\
Other & 745 & 1.62 & 0.78 \\
& & & \\
Returned & $\mathbf{4 9 , 0 7 6}$ & $\mathbf{1 0 0 . 0 0 \%}$ & $\mathbf{5 1 . 6 0 \%}$ \\
Short-term Rental & 23,415 & $47.71 \%$ & $24.62 \%$ \\
Collection Problem & 11,874 & 24.20 & 12.48 \\
Affordability & 7,192 & 14.65 & 7.56 \\
Exchanged & 4,588 & 9.35 & 4.82 \\
Loss of Income & 625 & 1.27 & 0.66 \\
No Payment Made & 616 & 1.26 & 0.65 \\
Service Problem & 499 & 1.02 & 0.52 \\
Other & 267 & 0.54 & 0.28 \\
& & & \\
Total Completed & & & $100.00 \%$ \\
Agreements & 95,113 & & \\
\hline
\end{tabular}

The detailed aggregated statistics on those agreements in the charged off and returned categories are shown in Table 2. As suggested from the examination of all agreements in the database, the number of agreements terminating with the merchandise being returned is far greater than the agreements charged off with the customer retaining the merchandise. Of the 95,113 total agreements in these two categories, 51.60 percent are terminated with the goods returned and 48.40 percent with the goods remaining with the customer. The hybrid rental-purchase nature of an RTO contract appears to be weighted towards the rental side of the agreement spectrum, a result opposite to the conclusion of the FTC and other researchers that emphasize the acquisition rather than the rental of merchandise.

The detailed statistics in Table 2 on payments to term also contradicts earlier findings based on small sample interviews. The transactional data shows that only 11.96 percent of all RTO agreements are completed to term. Efforts by consumer groups to require RTO contracts to indicate an implicit APR would not be the most useful information needed by almost 90 percent of those customers who do not make the entire scheduled series of rental payments. The proportion of customers who acquire the goods through an early single payment to purchase is greater, at 27.13 percent, than those who pay to term by more than a factor of two. Rather than focus on the relatively infrequent applicability of a contract's APR, it would be more helpful for RTO contracts to make sure consumers are fully cognizant of the purchase price at different points in time.

Combining the above figures on acquisition, 39.09 percent of all contracts are resolved with the consumer purchasing the item by renting to term or by a single early payment. This figure is dramatically lower than the comparable estimated purchase rate of 71.4\% percent reported in the FTC (2000) study on items rented more than two years before the survey. This very high purchase rate is given heavy emphasis in the FTC's testimony (2001) and is the basis for the recommendations on RTO legislation presented by Lacko, McKernan and Hastak (2002). This is not to say that the 39.09 of agreements that lead to eventual purchase by payments to term or by a single payment prior to term is insignificant. Furthermore, in an analysis of the database focusing on customers rather than transactions, $43.28 \%$ of customers purchased at least one item during the time period. The use of RTO for acquisition is a major outcome for consumers but the data also demonstrates that RTO functions to even greater degree as a shortterm source of the essential goods for household formation.

The transactional data in Table 2 also sheds a different light on the value to rent-to-own customers of the right to exercise the option to cancel an agreement. The FTC (2000) report discussed by Lacko, McKernan and Has- 
tak (2002) refers to an ultimate return rate of only $25 \%$. The result of the analysis of transactional data shows a return rate of $51.6 \%$, slightly more that twice the rate indicated by survey findings. The cancellation option appears to be of far greater value than would be implied by the FTC results.

The detailed results in the charged off and returned category are also particularly useful in highlighting certain aspects of an RTO operation understandably missed in interviewing past or current customers. As Table 2 indicates, 7.82 percent of all agreements and 24.71 percent of charged off agreements are terminated because the customer skipped by becoming unreachable and the merchandise unrecoverable. Due to the use of the interview methodology, the customer skipped proportion of agreements has escaped the attention of researchers. Another aspect of RTO operations brought out in Table 2 is the degree to which the business must focus on the management of credit risk. This risk arises in large part because of the standard industry policy of writing RTO agreements without a credit check or down payment. The effect of this policy is that for all contracts concluded, 12.48 percent were ended by the store due to a collection problem.

The primary reason for agreements terminating with the return of merchandise is for the customer expressing only a short-term need. The data in Table 2 indicates that 24.62 percent of concluded agreements -47.71 percent of all returns - were based on consumers using RTO to satisfy a temporary need. The FTC (2000) survey also confirms the important use of RTO agreements for short-term rentals as 40.1 percent of those returning indicated to store personnel that the goods were only needed temporarily. The Cheskin+Martin (1993) study, however, found that only 10 percent of RTO customers expressed the need for a short-term rental as a reason for an RTO agreement, the lowest proportion of all stated reasons in that study.

The data in Table 2 also shows consumers are satisfied with service but express greater dissatisfaction with affordability. Merchandise returns based on affordability were 14.65 percent of returns while few, 1.02 percent, cancelled due to poor service. This general high level of satisfaction with service by RTO dealers is also a feature of the FTC (2000) report. Swagler and Wheeler (1989), through their interviews of 61 customers, found that over onethird were unsatisfied with the overall RTO experience though not necessarily because of poor service or affordability alone.

\section{Duration Of RTO Agreements Based On Transactional Data}

The preceding analysis of the disposition of RTO agreements concluded that the return of merchandise is, by a slim margin, a more likely outcome than is charge off where the customer retains possession. RTO agreements closely resemble various forms of rental arrangements to the majority of customers rather than installment contracts or delayed purchases.

The installment model may still be applicable and APRs meaningful in some sense if the dealer usually recovers the merchandise only after the customer has made a long series of payments. Anecdotal evidence presented in courts, in legislative hearings, and developed in interviews, suggests that it is a common occurrence for RTO customers to make rental payments nearly to term and yet be required to return the merchandise for various reasons. (Martin and Huckins [1997]).

To address the issue of the number of payments made prior to termination, the transactional data was analyzed to determine the duration of a contract at the time it is concluded. The results of this duration analysis are shown in Table 3. For each category and sub-category, the median duration of the contract at the time of termination is presented as well as the $10 \%$ and $90 \%$ percentile. In addition, the ratio of the actual duration of each contract to its contractually scheduled term was calculated to gain further insight into the issue of whether RTO agreements are concluded early or late relative to term. The median value, along with the $10 \%$ and $90 \%$ percentiles, for this ratio for each classification and sub-classification is included. 
Table 3. Duration Of Agreement For Merchandise Charged Off Or Returned

\begin{tabular}{lrrrrrrr}
\hline Category & Number & \multicolumn{3}{c}{$\begin{array}{c}\text { Duration } \\
\text { (in Weeks) }\end{array}$} & \multicolumn{3}{c}{$\begin{array}{c}\text { \% Duration } \\
\text { to Scheduled Term }\end{array}$} \\
\hline Charged Off & & $\underline{10 \%}$ & $\underline{\text { Median }}$ & $\underline{90 \%}$ & $\underline{10 \%}$ & $\underline{\text { Median }}$ & $\underline{90 \%}$ \\
Purchased & $\mathbf{7 9 , 9 3 3}$ & $\mathbf{1 0 . 9}$ & $\mathbf{4 9 . 6}$ & $\mathbf{9 1 . 0}$ & $\mathbf{1 6 . 3 \%}$ & $\mathbf{8 2 . 5 \%}$ & $\mathbf{9 9 . 3 \%}$ \\
Payments to Term & 41,810 & 10.6 & 54.0 & 92.9 & 21.9 & 81.8 & 96.7 \\
Customer Skipped & 17,486 & 13.6 & 66.0 & 99.1 & 84.0 & 98.6 & 100.9 \\
Item Stolen & 17,316 & 10.7 & 25.9 & 69.7 & 12.3 & 35.4 & 90.4 \\
Item Damaged & 975 & 6.3 & 18.6 & 57.1 & 8.1 & 27.9 & 85.9 \\
Other & 871 & 4.4 & 16.6 & 59.6 & 5.3 & 21.4 & 72.1 \\
& 1,475 & 15.4 & 68.3 & 91.7 & 20.8 & 98.7 & 100.0 \\
Returned & & & & & & & \\
Short-term Rental & $\mathbf{1 8 6 , 9 9 8}$ & $\mathbf{0 . 6}$ & $\mathbf{5 . 9}$ & $\mathbf{3 0 . 3}$ & $\mathbf{0 . 5}$ & $\mathbf{6 . 9}$ & $\mathbf{3 5 . 7}$ \\
Collection Problem & 89,615 & 0.4 & 4.0 & 26.7 & 0.3 & 4.8 & 30.9 \\
Affordability & 38,345 & 3.3 & 10.9 & 37.9 & 3.3 & 12.6 & 44.8 \\
Exchanged & 26,461 & 1.9 & 8.1 & 32.4 & 1.6 & 10.0 & 39.8 \\
Loss of Income & 19,912 & 0.1 & 2.7 & 25.6 & 0.1 & 3.0 & 28.9 \\
No Payment Made & 5,355 & 2.0 & 7.0 & 23.6 & 2.4 & 8.6 & 29.8 \\
Service Problem & 2,645 & 1.4 & 3.3 & 6.4 & 1.0 & 3.7 & 8.5 \\
Other & 1,622 & 0.1 & 3.0 & 34.0 & 0.2 & 3.5 & 40.5 \\
\hline
\end{tabular}

The statistics are reported for $10^{\text {th }}$ percentile, median and $90^{\text {th }}$ percentile of the sample, respectively.

The data shown in Table 3 reveals a sharp distinction in duration between merchandise charged off and returned. Agreements that conclude with the return of merchandise have a median duration of 5.9 weeks while agreements ending with the customer in possession have a median duration of 49.6 weeks — over eight times as long. An examination of the percentile information confirms the significant divergence in durations of returns and charge offs. In the returns category, the $90^{\text {th }}$ percentile of agreements have a duration of 30 weeks or less while this percentile in the charge offs classification is 91 weeks or less. The $10^{\text {th }}$ percentile also sharpens the distinction between the duration of outcomes with $10 \%$ of returns occurring almost immediately in less than one week while $10 \%$ of charge-offs occur in about eleven weeks or less.

The median time for goods purchased by a single payment prior to term is 54.0 weeks with a median of 81.8 percent of the contractual time. The customer skipping event has a median time of 25.9 weeks with a corresponding median of about one-third of the way towards term suggesting that those who plan to walk away with the merchandise do not do so immediately. Agreements terminated because the item is stolen or damaged have a median duration between 16 and 19 weeks.

The durations reported for returns suggest that both RTO customers and store managers are apt to make a decision very early on to return or recover merchandise. Consumers using RTO to fill a short-term need have a median return time of 4.0 weeks. Managers who detect a serious collection problem compel a return with a median time of 10.9 weeks into the contract. Merchandise returns due to a customer realizing the RTO agreement is unaffordable occur with a median time of 8.1 weeks.

The short median duration of agreements leading to a merchandise return implies that few payments were made in relation to the entire term of the contracts. The percentile data shows that $90 \%$ of returns occur with less than $36 \%$ of the scheduled weekly payments made. The scenario of customers returning goods after nearly reaching the term of an RTO contract is not one that can be validated as a common occurrence. The median and percentile durations are only long where expected-i.e., when the good is purchased for a percentage of the remaining payments or the payments are completed to term. Where goods are returned, it is within a short period of time, generally not more than 10 percent of the total time to completion. The rental characteristics of RTO and the value of the 
embedded options are clearly apparent in this category. The duration evidence suggests that the installment model has limited applicability as guidance for regulators, advocates, consumers and rent-to-own store managers in their comprehension of how RTO agreements are used in the financial marketplace.

\section{Conclusion And Policy Recommendations}

The transactional evidence strongly suggests that an RTO agreement is used by a majority of customers to satisfy an immediate need and who value highly the embedded options to cancel without financial repercussions. Current perceptions of RTO, based on consumer interviews by the FTC and others, overstate the degree to which RTO results in the purchase of merchandise by payments to term or by a single early payment.

The short-term, rental nature of over 51 per cent of RTO agreements is supported by an analysis of the duration. When merchandise is returned, for whatever reason, it is done early in the term of the agreement before many payments are made. A very high proportion of those who return merchandise typically do so after making fewer than 10 percent of the scheduled payments. Consumers who complete most of their rental payments are highly likely to gain possession of the merchandise by exercising the early payment option rather than returning it to the dealer. The data does not support the view that a significant number of RTO customers are eventually forced to return merchandise despite faithfully completing nearly all scheduled payments.

The transactional data also clarifies and perhaps corrects the conventional portrayal of the RTO business. An inaccurate portrayal of the business is that it rents out primarily new merchandise still under manufacturers' warranty and most of this merchandise is acquired by consumers after the store collects a long series of payments to term. This study shows that the RTO is heavily involved in servicing, receiving or recovering, refurbishing and rerenting returned goods. A significant proportion of the goods have been used previously and, due to the high probability of return, a new agreement on the same merchandise cannot ordinarily be expected to generate rental payments for an extended period of time.

It is also unrealistic to contend that the RTO business assumes little risk despite the absence of credit checks and down payments because merchandise is recovered whenever a payment is not remitted promptly. Attempts by RTO dealers to recover merchandise are not immediately or always successful and the recovered merchandise may be severely impaired. The transactional data reveals that a significant amount of merchandise is never recovered despite a complete cessation of customer payments. This skipped category represents 7.82 percent of concluded contracts and 16.15 percent of contracts charged off. For the 12.48 percent of completed contracts24.20 percent of charged off contracts - ended due to collection problems, it is uncertain whether the dealer ultimately received all payments due at the time of recovery.

From a public policy standpoint, mandating RTO retailers tag each item with a calculated implied APR might be helpful in less than 12 percent of all agreements that are fully paid to term. In addition, retailers can readily manipulate APRs by simply adjusting the item's list price. A straightforward APR computation also disregards the hybrid rental and purchase aspects of RTO by excluding the value of the frequently exercised embedded options that are an integral part of the agreement. These options are inherently of value to the customer whether or not they are in fact exercised.

The transactional data can support a recommendation that RTO agreements clearly convey the item's purchase price at any point in time. Far more agreements involve the exercise of the purchase option rather than payments to term and a schedule of purchase prices clearly conveys essential information. In addition, the agreement should accurately reveal the condition of the merchandise as new, used, reconditioned, refurbished and the like. Based on the high frequency of returns, there is severe information asymmetry on the condition and history of the merchandise in inventory. Customers would benefit from industry standards for accurately describing the condition of the goods scheduled for delivery and this description should be prominently displayed and understood at the time an agreement is negotiated. 


\section{References}

1. Anderson, Michael H. and Raymond Jackson, “A Reconsideration of Rent-to-Own”, Journal of Consumer Affairs, Vol. 35, pp. 295-307, 2001.

2. $\quad$ APRO, "Industry Revenue Exceeds \$5 Billion", View, September 4, 2001.

3. Cheskin+Martin, "Rent-A-Center Longitudinal Research in Rent-to-Own: Providing Opportunities or Gouging Consumers?", Submitted to the Committee on Banking, Finance and Urban Affairs, House of Representatives, $103^{\text {rd }}$ Congress, $1^{\text {st }}$ Session. Serial No. 103-24. Washington, DC: U.S. Government Printing Office, pp. 441-546, 1993.

4. $\quad$ Federal Reserve Board, "Testimony of Federal Reserve Officials", Federal Reserve Bulletin, Vol. 87, pp. 586-599, 2001.

5. Federal Trade Commission, Survey of Rent-to-Own Customers, by James M. Lacko, Signe-Mary McKerman and Manoj Hastak, Washington DC, 2000.

6. Federal Trade Commission, "Prepared Statement of the Bureau of Economics by H. Beales III on Rent-toOwn Transactions", Financial Institutions and Consumer Credit Subcommittee, House Financial Services Committee, Washington, DC, July 12, 2001.

7. Freedman, Alix M., "Peddling Dreams: A Marketing Giant Uses Its Sales Prowess to Profit on Poverty", Wall Street Journal, (1993), pp. A1, A10, September 22, 1993.

8. Hill, Ronald Paul, David L. Ramp, and Linda Silver, "The Rent-to-Own Industry and Pricing Disclosure Tactics", Journal of Public Policy and Marketing, Vol. 17, pp. 3-10, 1998.

9. Lacko, James M., Signe-Mary McKernan, and Manoj Hastak, "Customer Experience With Rent-to-Own Transactions", Journal of Public Policy and Marketing, Vol. 21, pp. 126-138, 2002.

10. Martin, Susan Lorde and Nancy White Huckins, "Consumer Advocates vs. the Rent-to-Own Industry: Reaching a Reasonable Accommodation", American Business Law Journal, Vol. 34, pp. 385-428, 1997.

11. Ramp, David L., "Written Statement in Hearing Before the Committee on Banking, Finance and Urban Affairs", House of Representatives, $103^{\text {rd }}$ Congress, ${ }^{\text {st }}$ Session, Serial No. 103- 24. Washington, DC: U.S. Government Printing Office, pp. 244-266, 1993.

12. Swagler, Roger M., and Paula Wheeler, "Rental-Purchase Agreements: A Preliminary Investigation of Consumer Attitudes and Behaviors", Journal of Consumer Affairs, Vol. 23, pp. 145-160, 1989.

13. Walden, Michael L., "The Economics of Rent-to-Own Contracts", Journal of Consumer Affairs, Vol. 24, pp. 326-337, 1990.

14. Zikmund-Fisher, Brian J. and Andrew M. Parker, "Demand for Rent-to-Own Contracts: A Behavioral Explanation”, Journal of Economic Behavior and Organization, Vol. 38, pp. 199-216, 1999. 